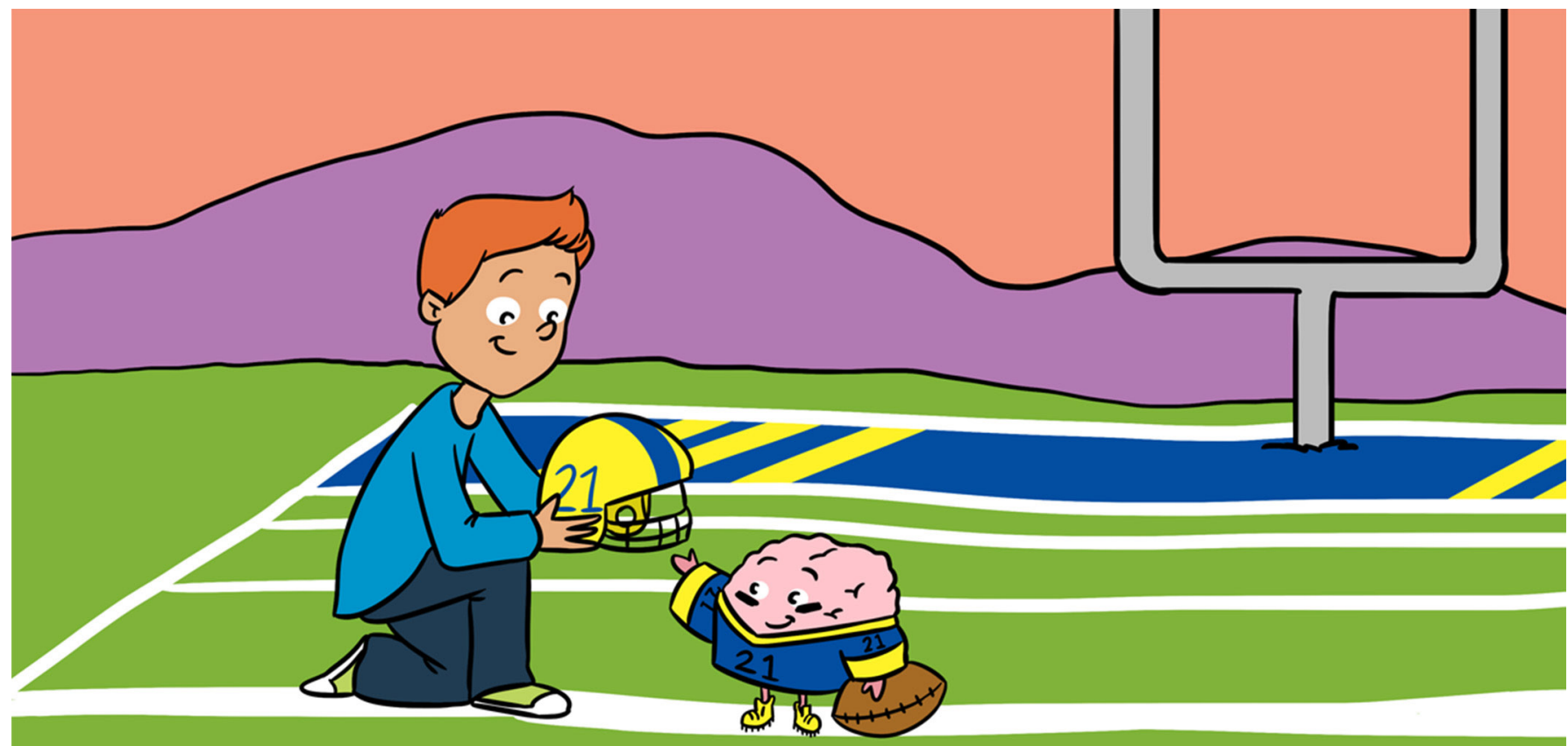

\title{
PREVENTING THE BRAIN FROM BEING INJURED
}

\section{Daniela Flores*, Sabine Delouche and Gillian Hotz}

Kidz Neuroscience Center at University of Miami, Miami, FL, United States

\section{YOUNG REVIEWERS:}

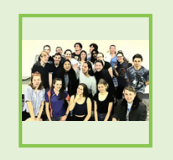

STEM

CONNECT RESIDENTIAL CAMP

AGES: $14-15$

TRAUMATIC BRAIN INJURY

A disruption in the normal function of the brain that can be caused by an external force such as a hit to the head.
The brain controls much of what we do in our everyday lives. Because the brain controls almost everything you do, it is important to protect it and prevent it from being injured. Injury prevention is important, because traumatic brain injuries can result in long-term negative effects when they are not diagnosed and treated properly. Often, children and even their parents are not aware of the symptoms resulting from a traumatic brain injury, and this can lead to a delay in treatment. By understanding how injury prevention works and the methods used, you can reduce your risk of injury and keep your brain healthy.

\section{WHAT IS TRAUMATIC BRAIN INJURY?}

Your brain controls everything you do and everything that goes on in your body. It controls how you walk, how you talk, and how you learn; it even controls how hungry you are! Like any other part of your body, sometimes your brain can get injured. When your brain gets injured, it is called a traumatic brain injury (TBI). TBI happens when something outside of your body hits you hard enough to hurt your brain. 


\section{CONCUSSION}

A mild traumatic brain injury caused by a bump, blow or jolt to the head causing the brain to move rapidly back and forth.

\section{Figure 1}

The red areas show where the brain impacts the skull during the initial impact and the secondary impact as a result of hitting your head or body hard enough.
When someone experiences TBI, that person can have problems that last a long time, sometimes even forever. TBI can change the way you think, remember things, and learn things. It can change the way you move and the way you speak, hear, or see. It can also change your emotions and your personality.

One type of TBI is called a concussion. You can get a concussion when something hits your head or body hard enough to knock your brain around inside of your skull [1]. In a concussion, the brain experiences an initial impact on the part of the skull that is hit, due to acceleration or quickly moving forward, and a second impact on the opposite side of the skull, from the deceleration or rebound from the initial impact, as shown in Figure 1. You can get a concussion from playing sports such as American football, ice hockey, boxing, skiing, or even soccer. A concussion can also happen if you crash while riding a bike without a helmet, or if you are in a car accident.

Some common symptoms of concussion include:

- Headaches

- Dizziness

- Trouble balancing

- Being bothered by light or noise

- Confusion

- Having a hard time concentrating

- Feeling nauseous (sick to the stomach)

- Having trouble remembering things

- Having trouble sleeping

- Personality changes

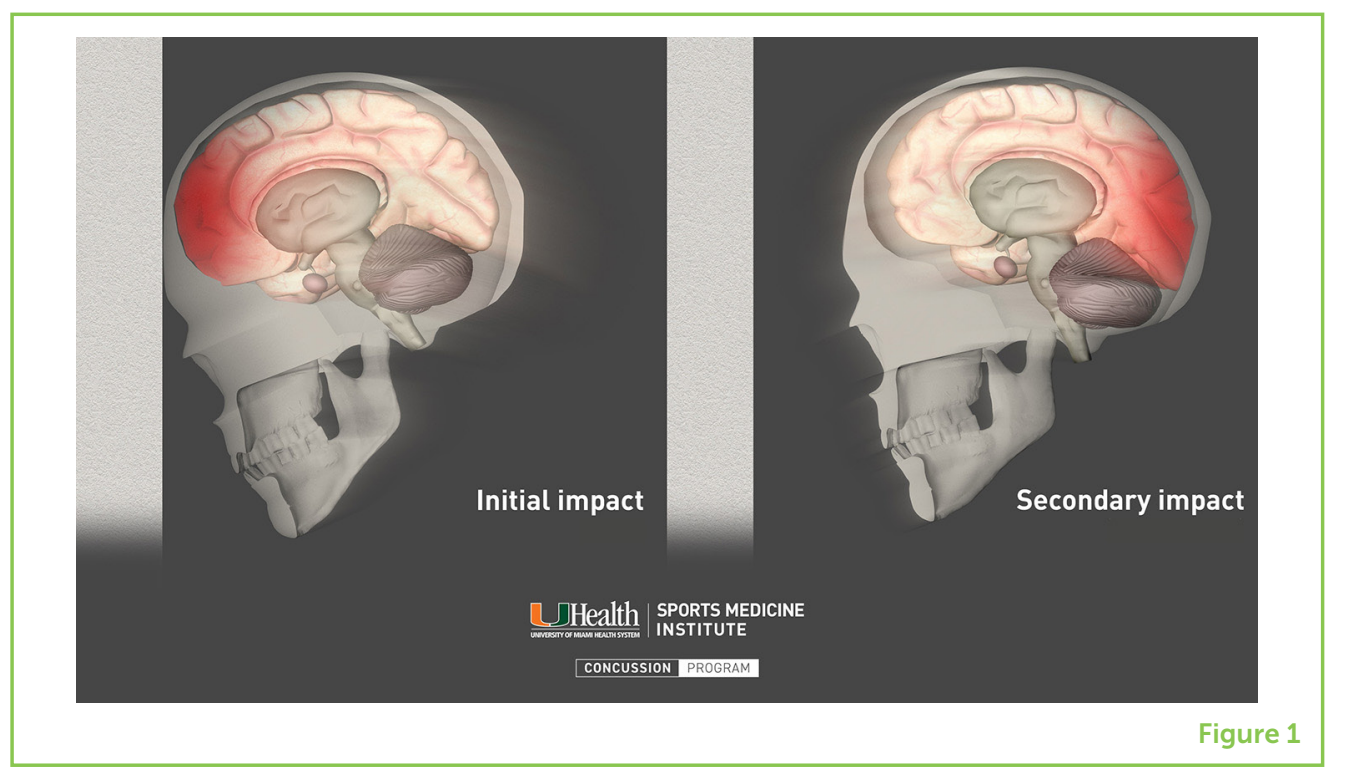


Figure 2

Common concussion symptoms.

\section{INJURY}

PREVENTION

Efforts focused on identifying and preventing the causes of injuries.

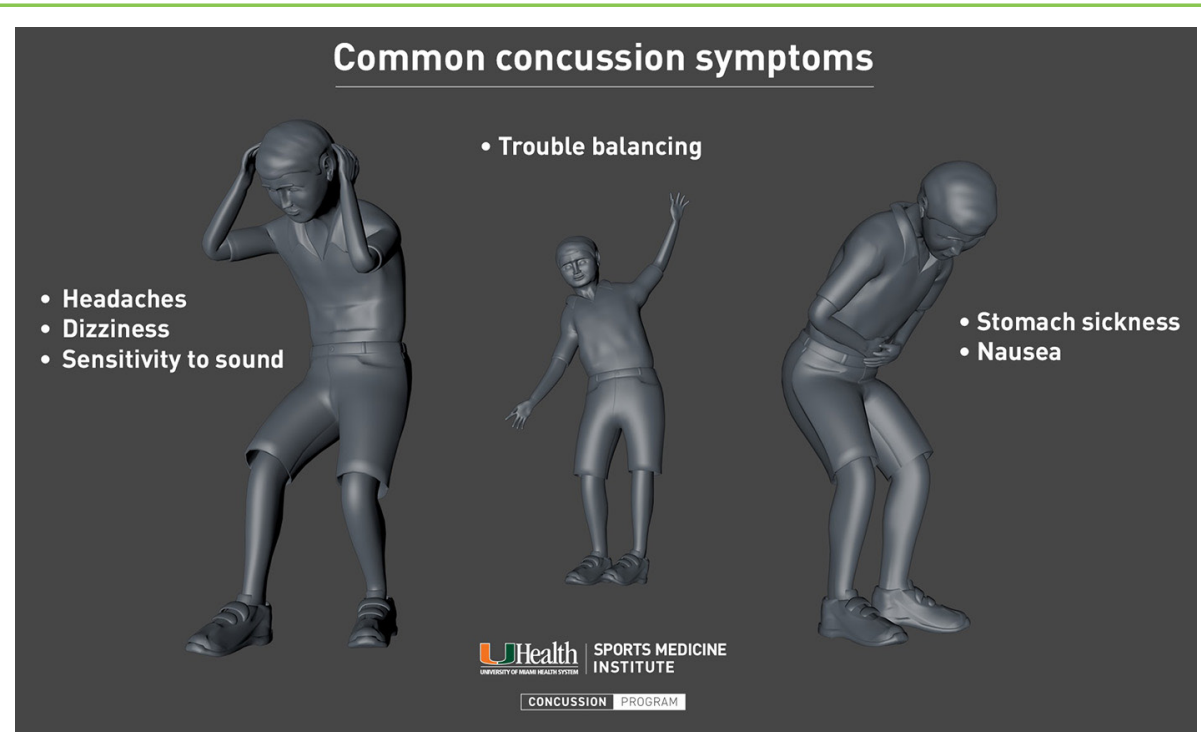

Figure 2

These symptoms, which are also illustrated in Figure 2, are all pretty scary! If you hit your head and experience these symptoms, it is very important to seek medical attention.

The good news is that brain injuries like concussions are preventable, and they can be diagnosed and treated by a doctor. In fact, there are programs dedicated to treatment of concussions, like the KiDz Neuroscience Center at the University of Miami (KNC). KNC focuses on reducing the number of children and adolescents that experience brain and spinal cord injuries. Keep reading, to learn about different injury prevention models and how programs like KNC use these injury prevention models to reduce the incidences of TBI in their communities.

\section{LEVELS OF BRAIN INJURY PREVENTION}

Brain injury prevention focuses on ways to minimize these injuries in everyday life. There are three levels of prevention: primary (or first), secondary (or second), and tertiary (or third).

The goal of primary prevention is to stop a brain injury from happening in the first place. This is done by reducing the risk of exposure to an injury. An example of primary prevention is teaching athletes about tackling and heading techniques to prevent TBI while playing football.

If someone already has a brain injury, secondary prevention is used to keep that injury from getting worse. Having a doctor examine you for a concussion after a hit to the head, called "screening," is an example of secondary prevention. 
The last level of prevention is tertiary. Tertiary prevention is used to lessen the effects of a brain injury. The CDC has new guidelines on mild traumatic brain injury (mTBI) among children, which include 19 recommendations relating to diagnosis, prognosis (outcome), and the management/treatment of pediatric mTBI [2]. These guidelines are examples of tertiary prevention. The recommendations include rest, assistance with school work (giving extra time to complete assignments), and proper sleep methods. All of these can help with recovery.

\section{THE 6-E MODEL OF INJURY PREVENTION}

Brain injury prevention programs use something called the "6-E Model" to make sure everything possible is being done to stop injuries from happening. The 6 E's stand for education, engineering, enforcement, encouragement, equity, and evaluation. When all of these pieces work together, more brain injuries are prevented.

Education is used to teach an individual what they can do to stay brain injury-free. Effective education about TBI prevention can include learning how to be safe while playing sports, like the football tackling techniques shown in Figure 3, learning how to properly ride a bicycle, and learning how to safely cross the street, as a pedestrian.

Engineering consists of making changes to the environment that will reduce the chances of someone getting hurt. The environment includes the places that you play and live in, the roads you travel on, or even the equipment you use. A newly designed helmet that absorbs

\section{Figure 3}

The figure shows two football tackling techniques: spearing and heads-up. It demonstrates the spearing technique as incorrect and the heads up technique as correct tackling technique. The heads up technique avoids direct contact with the head and decreases the chances of injury.

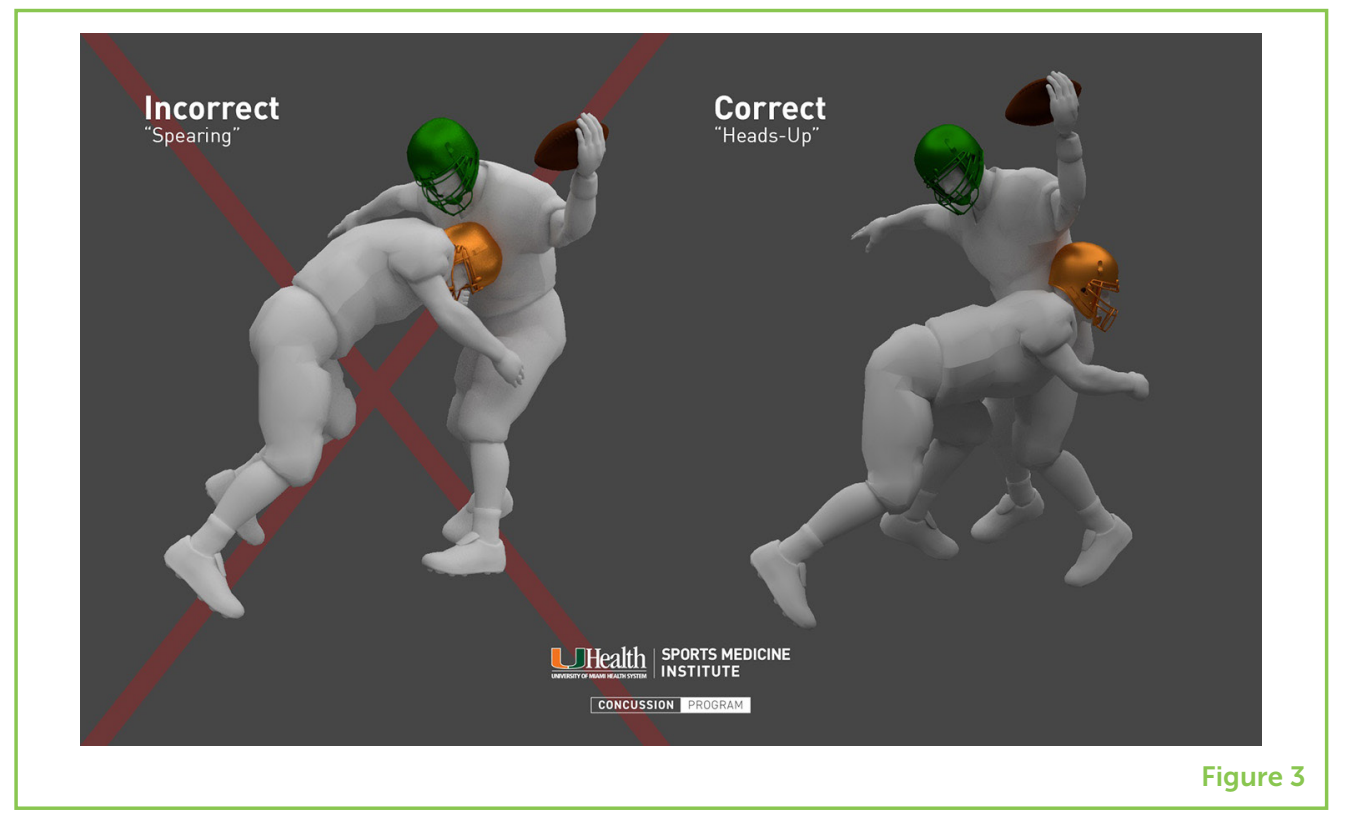


the shock of a hit, and bikes-only lanes on the road to lower the chances of being hit by a car are both examples of using engineering to prevent injuries.

Enforcement enlists the help of lawmakers and police officers to make and enforce policies that reduce TBI incidents. This includes passing laws that help keep everyone safe and using police officers to make sure people follow those laws. Examples of enforcement are police officers giving tickets to people who do not wear seat belts in their cars or requiring children to wear helmets while riding bicycles.

Encouragement creates awareness, by getting people excited about activities like walking and biking, especially when those activities are done in a safe way. Encouragement can be done by giving out prizes, like earning points, each time someone crosses the street safely using the crosswalk.

Equity means giving everyone a chance to benefit from an activity. It also means finding out which things keep people from being safe and trying to fix them. For example, if a child cannot afford a helmet, an injury prevention program can give that child a helmet for free.

Lastly, evaluation, like a report card, checks that safety and prevention programs are actually meeting the needs of the community and working the way they are supposed to. This evaluation step helps to address and fix the things that are not working well.

\section{BRAIN INJURY PREVENTION PROGRAMS AT UNIVERSITY OF MIAMI}

Now that you have learned about the levels of injury prevention and the 6 -E model, let us take a look at some programs that exist. The KiDZ Neuroscience Center (KNC) at the University of Miami has three programs that work to reduce the number of brain and spinal cord injuries in children and teenagers. These programs were created in 2001 because of the high number of pediatric (ages $0-14$ ) brain injuries seen at the Ryder Trauma Center. Each of these programs uses all three levels of injury prevention in Miami-Dade County, Florida.

1. The first program is UConcussion (www.uconcussion.com). This program includes two clinics, which focus on the secondary and tertiary levels of prevention. The Pediatric mTBI Concussion Clinic helps children 5-16 years old with all injuries that result in concussions. The Sports Concussion Clinic helps high school and college athletes who have a sports-related concussion. 
2. The second program is WalkSafe (www.iwalksafe.org). This program teaches elementary school-age (5-10) children how to be safe pedestrians, by teaching them important skills like how to cross the street. This program falls under the primary level of prevention, because it focuses on education and tries to stop injuries before they happen. Children can practice the skills they learn from WalkSafe at school first, before using those skills in their day-today lives.

3. The last program is BikeSafe (www.ibikesafe.org). This program teaches middle school-age (10-14) children important bike safety skills. Children learn how to wear their helmets properly, how to check their bikes before going on a ride, rules of the road, and the different hand signals that should be used while bicycling. Just like the WalkSafe program, BikeSafe falls under the first level of prevention.

In addition to these programs that address all three levels of injury prevention, WalkSafe and BikeSafe also use the 6-E model. As result of the efforts of these programs, there has been a $78 \%$ decrease in pediatric pedestrians hit by cars and a $30 \%$ decrease in pediatric bicyclists hit by cars in Miami-Dade County. The programs have accomplished this by working together with local government officials (like the mayor), traffic planners, school districts, and communities. Strong relationships with these different partners help the programs work toward improvements to bike paths, roads, sidewalks, and school environments, to make the environment safer for young people like you!

\section{CONCLUSION}

You are now prepared to help prevent brain injuries from happening to you and to those around you. You have learned what a concussion is, what the symptoms are, and how concussions can happen. Even if you think you are not at risk for getting a TBI, accidents can happen, and this is valuable information to help keep your brain healthy.

\section{REFERENCES}

1. Centers for Disease Control and Prevention. 2016. Traumatic Brain Injury \& Concussion. Available online at: www.cdc.gov/traumaticbraininjury/basics. html

2. Lumba-Brown, A., Yeates, K. O., Sarmiento, K., Breiding, M. J., Haegerich, T. M., Gioia, G. A., et al. 2018. Centers for disease control and prevention guideline 
on the diagnosis and management of mild traumatic brain injury among

children. JAMA Pediatr. 172:e182853. doi: 10.1001/jamapediatrics.2018.2853

SUBMITTED: 21 September 2018; ACCEPTED: 25 January 2019;

PUBLISHED ONLINE: 13 February 2019.

EDITED BY: Amy J. Markowitz, University of California, San Francisco, United States

CITATION: Flores D, Delouche S and Hotz G (2019) Preventing the Brain From Being Injured. Front. Young Minds 7:18. doi: 10.3389/frym.2019.00018

CONFLICT OF INTEREST STATEMENT: The authors declare that the research was conducted in the absence of any commercial or financial relationships that could be construed as a potential conflict of interest.

COPYRIGHT (c) 2019 Flores, Delouche and Hotz. This is an open-access article distributed under the terms of the Creative Commons Attribution License (CC BY). The use, distribution or reproduction in other forums is permitted, provided the original author(s) and the copyright owner(s) are credited and that the original publication in this journal is cited, in accordance with accepted academic practice. No use, distribution or reproduction is permitted which does not comply with these terms.

\section{YOUNG REVIEWERS}

\section{STEM CONNECT RESIDENTIAL CAMP, AGES: 14-15}

The STEM Connect Residential Camp was an experiential education program offering Year 10 students from nine schools, 3 days of exposure to exciting and rewarding study of Science, Technology, Engineering, and Mathematics (STEM) on the Sunshine Coast. The STEM sessions targeted enterprise skills such as creative thinking and problem solving, digital proficiency, and science communication.

\section{AUTHORS}

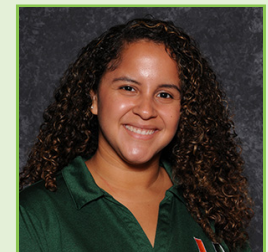

\section{DANIELA FLORES}

I am most interested in working to improve the well-being of children. Before working for the University of Miami WalkSafe program, I worked in the Foster care system as an Advocate for children who were abused and neglected. Now that I have gained experience in injury prevention and brain injury research, I want to continue learning and exploring these topics. During my spare time, you can find me hanging out at the beach or trying out new restaurants around Miami. *dfloresamed.miami.edu 


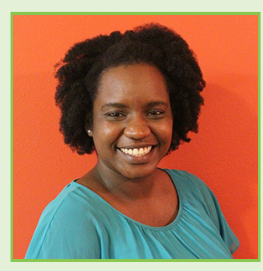

\section{SABINE DELOUCHE}

I am a recent graduate of Public Health, and am learning so much about prevention and working to keep populations safe and healthy. My favorite part of public health is getting to interact with people of all different backgrounds and ages. When I am not at the office, you can find me dancing to salsa music, traveling, and trying out new foods! I love adventure, and enjoy getting to learn more about people, their environments, and what makes them happy.

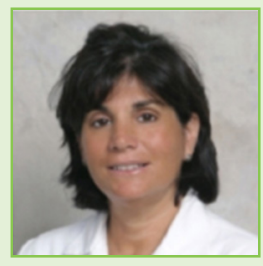

\section{GILLIAN HOTZ}

I grew up in Ontario, Canada where most kids play hockey, skate, or ski. I was always getting injured myself from playing these sports and started thinking about what could be done to prevent these injuries. In college, I studied Neuroscience at Boston University where I learned all about the brain and brain injury. After I finished my Ph.D., I started working at the Ryder Trauma Center in Miami where I directed a Pediatric Brain Injury Program where we treated children with traumatic brain injuries. We put a multidisciplinary team together to figure out how to prevent these injuries of children that get hit by cars, are injured on a bicycles and skate boards and also playing sports. 